\title{
Comparing Mobile Phone Price Estimators in the IranMarket: Hedonic Regression and Artificial Neural Network
}

\author{
Dr. Mohsen Nazari \\ Faculty member in Faculty of Management, University of Tehran, Tehran, Iran \\ Tel: 98-21-6111-7652Ｅ-mail: Mohsen.nazari@ut.ac.ir
}

Seyed Vahid Tabatabaie Kalejahi(corresponding author)

Department of Business Administration

Faculty of Management, University of Tehran, Tehran, Iran

Tel: 98-21-6111-7652_E-mail: Tabatabaie@ut.ac.ir

Received: Nov. 15, 2011 Accepted: November 28, $2011 \quad$ Published: December 18, 2011

doi:10.5296/bms.v3i1.1083

URL: http://dx.doi.org/10.5296/bms.v3i1.1083

\begin{abstract}
The purpose of this paper is to develop two price estimator functions and compare the performance and accurateness of them.After gathering mobile phone features from their manufacturers' websites and their prices from "Donyaye-Eqtesad" newspaper, Hedonic regression and Artificial Neural Network models developed.The most effective feature of mobile phones in their prices are theirs brand, being touch screen, camera quality in mega pixel, battery life in calling and wireless network connectivity, and Also ANN model is better estimator than hedonic regression function.Because all of the mobile phones in the Iran market are imported from other countries, importers can import mobile phones that have those features that have more value to customers and reach a higher market share.The major contribution of this paper is specifying the most important determinants of mobile phone prices in the Iran market and comparing the two price estimator functions. This paper is of value to mobile phone importers, mobile phone manufactures, advertisers and pricing researchers.
\end{abstract}




\section{Macrothink

Keywords: Hedonic pricing analysis, Artificial neural network, Regression analysis, Mobile phone, Iran 


\section{Introduction}

The demand of mobile phone is considerably increasing in the Iran market as well as other countries. Mobile phone is a daily necessity for Iranian. Every day, the competition between mobile phone suppliers gets fiercer. Market share of mobile phone suppliers vary heavily month to month. Nevertheless little formal empirical analysis has been established on the determinants of mobile phone prices in the Iran market. This paper's aim is to fill this gap and provide a formal statistical analysis of different mobile phone prices. Specifically, an empirical hedonic price analysis with modeling by Artificial Neural Network is performed, using data on 101 different mobile phones from 5 manufacturers.

Mobile phone characteristics and features such as weights were collected from their manufactures' website. Also mobile phone prices were gathered from the daily newspaper "Donyaye-Eqtesad" in 9/15/2010. This newspaper everyday publishes the price of many goods and services in Tehran's market. In order to estimate hedonic price for various features, (OLS) linear regression was used. Also the price function is modeled by ANN.

One of the four elements of marketing mix is pricing. One of the important decisions any business faces is selecting pricing strategies that can be effective in achieving company's goal. Hedonic Pricing method is one of the pricing methods that is suitable for multi-feature goods and services. In Iran, all mobile phone suppliers import them from other countries and distribute them in the market. This paper helps them to know which feature of mobile phones has more value to customers. Then they can import mobile phones that have those features and reach a higher market share. Also the Hedonic function is useful in pricing the mobile phone in the market.

\section{Hedonic Regression}

The hedonic price theory and its theoretical and statistical foundation are in the works of (Lancaster K. , 1966), (Rosen, 1974), and (Feenstra, 1995) see in (Thrane, February 2005). This theory's hypothesis is that the price of a product is a function of its attributes. A classical suitable case concerns cars, where the price of a car can be viewed as a function of, for example, its manufacturer's nationality, its size, its engine's performance, or its "subjective" quality (cf. (Triplett, 1969)) (Thrane, February 2005). Another example would be the mobile phone.

Hedonic methodology is mainly used for the market valuation of goods for their utility-bearing characteristics. The goods under consideration embody varying amounts of attributes and are differentiated by the particular attribute composition that they possess. In most cases, the attributes themselves are not explicitly traded, so that one cannot observe the prices of these attributes directly. In such a case, hedonic pricing models are very essential in order to determine how the price of a unit of commodity varies with the set of attributes it possesses. If the prices of these attributes are known, or can be estimated, and the attribute composition of a particular differentiated good is also known, hedonic methodology will provide a framework for value estimation (Selim, 2009)see (Ustaoglu, 2003). 
Another important assumption is that consumers have preferences over those attributes. There are maximum amounts that they are willing to spend, these are known as the consumer's willingness to pay(WTP) for any given good or service they buy. This bid depends upon the consumers' preferences as well as the bundle of characteristics. On the other hand, producers choose the bundle that maximizes their profits subject to the price of inputs, the production function, and the market price for each alternative bundle of characteristics. Thus, the producer's offer or willingness to accept the function indicates the minimum unit price the producer will accept for those services. The prices seen in the market are their tangency points since the market equilibrium is the tangency of these bid and offer functions (Lee, Park, \& Kim, 2003) see (Rosen, 1974) (Asher, 1992) (Nerlove M. , 1995).

According to Rosen's (Rosen, 1974) setting, a mobile phone can be understood as a vector(bundle) of attributes

$\mathrm{C}=\left(\mathrm{c}_{1}, \mathrm{c}_{2}, \mathrm{c}_{3}, \ldots, \mathrm{c}_{\mathrm{N}}\right)$,

wherec $_{\mathrm{n}}$ is the $\mathrm{n}$-th attribute of mobile phone, like its weight. Clearly, mobile phone importers can import those mobile phones that have high-value attributes (Rigall-I-Torrent \& Fluvia, 2010).

Because the overall price of the mobile phone is assumed to be a function of its attributes, the hedonic price function becomes as follows:

$\mathrm{P}(\mathrm{C})=\mathrm{P}\left(\mathrm{c}_{1}, \mathrm{c}_{2}, \mathrm{c}_{3}, \ldots, \mathrm{c}_{\mathrm{N}}\right)$

In the typical case, the price of, for example, a hotel room is empirically modeled as the additive function of various objective hotel attributes (e.g., type of board, distance to downtown, distance to amusement parks, and presence of swimming pool, sauna, bar, and restaurant) and more subjective attributes (e.g., service quality, atmosphere, and hotel star rating). Usually, this model is estimated by means of OLS regression or some related technique(Thrane, February 2005).

\section{Artificial Neural Networks}

Selecting a precise form of hedonic function is an important issue in hedonic literature. Because of that issue, Artificial Neural Network modeling comes into consideration. The concept of 'universal approximation', which is used, e.g. by Hornik, Stinchcombe, and White (1989)see in (Selim, 2009) is fundamental to the practical application of ANN models. Keep it simple, this means that the networks are capable of adapting to arbitrary and unknown functional forms, with an arbitrarily specified degree of precision. Universal approximation leads us towards regarding neural networks generally as flexible non-linear statistical methods (Curry, Morgan, \& Silver, 2002) see in (Selim, 2009)

In this paper the feed forward network is employed. Such network model can be viewed as a flexible non-linear regression. The term 'non-parametric regression' may also be adopted. The ANN models use the same input and output parameters as in the linear models. These 
models have three primary components: the input data layer, the hidden layer(s) and the output measure(s) layer. Each of these layers contains nodes, and these nodes are connected to nodes at adjacent layer(s). The hidden layer(s) contain two processes: the weighted summation functions and the transformation function. Both of these functions relate the values from the input data to the output measures. The weighted summation function is typically used in a feed-forward/back propagation neural network model.Figure 1 demonstrates a simplified neural network. (Selim, 2009)

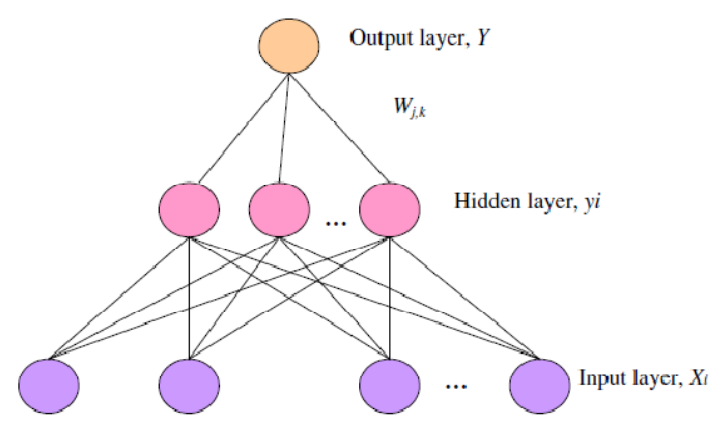

Figure 1. A neural network model

\section{Related Works}

\subsection{Hedonic Regression}

The summary of previous studies in hedonic pricing is illustrated in table 1 .

Table 1Summary of previous studies in Hedonic Pricing

\begin{tabular}{|l|l|}
\hline Studies & Case \\
\hline (Waugh, 1928) & Asparagus \\
\hline (Berry, Levinsohn, \& Pakes, 2004) & Automobile \\
\hline (Haeger \& Storchmann, 2006), (Nerlove M. , 1995) & Wine \\
\hline $\begin{array}{l}\text { (Maurer, Pitzer, \& Sebastian, 2004), (Sue \& Wong, } \\
\text { 2010) }\end{array}$ & Housing \\
\hline $\begin{array}{l}\text { (Thrane, February 2005), (Rigall-I-Torrent \& Fluvia, }, \\
\text { 2010),(Hung, Shang, \& Wang, 2009) }\end{array}$ & Tourism and Hotel \\
\hline (Chwelos, Berndt, \& Cockburn, 2006), (Pakes, 2003) & PDA, PC \\
\hline (Dewentet, Haucap, Luthar, \& Rotzel, 2007) & Mobile Phone \\
\hline (Lee, Park, \& Kim, 2003) & Internet \\
\hline (Chakravarty, Dogan, \& Tomlinson, 2006) & $\begin{array}{l}\text { Network effects for } \\
\text { word } \\
\text { software }\end{array}$ \\
\hline (Bonnetain, 2003) & Island \\
\hline
\end{tabular}

\subsection{Artificial Neural Networks}

Jandaghi and Hashemi in 2010 used probabilistic neural networks and discriminant analysis 
in modeling the selection of a product through its attributes. Their findings show that neural network tool is more power than discriminant analysis tool in this modeling and neural network needs less variables that discriminant analysis for modeling (Jandaghi \& Hashemi, 2010). Ali İşeri and BekirKarlık used Artificial Neural Network approach on automobile pricing. Their proposed novel model estimates prices of automobiles on a stable market from their technical and physical properties (İşeri \& Karlık, March 2009). Pao in 2007 for forecasting long-term electricity market pricing, in order to avoid excessive round-off and prediction errors, proposed a new artificial neural network (ANN) with single output node structure by using direct forecasting approach. The proposed ANNs are a more robust multi-step ahead forecasting method than autoregressive error models. Moreover, ANN predictions are quite accurate even when the length of the forecast horizon is relatively short or long. (Pao, March 2007). Shin-Yuan Hung et al developed an innovative approach that integrates the arbitrage pricing theory (APT) and artificial neural networks (ANN) to support portfolio management. The integrated approach takes advantage of the synergy between APT and ANN in extracting risk factors, in predicting the trend of individual risk factor, in generating candidate portfolios, and in choosing the optimal portfolio. Empirical results indicate that the integrated method beats the benchmark and outperforms the traditional method that uses the ARIMA model (Hung, Liang, \& Liu, November 1996).

\subsection{Mobile Phone Market}

The aim of Thakur's paper(2011) is the understanding of how competition based telecommunicationpolicies function as a mediating variable in the distribution of socio-economic consequences ofmobile phones using the case of Canada. Many claim that the Canadian market is uncompetitive, and argue that this lack of competition has affected Canadians in terms ofaccess. Thus, even though almost all Canadians have access to land-line services, mobile phonepenetration is still relatively low. This article also argues that competition needs to be alignedwith the overall vision of telecommunications policy. To do this, a country needs to define what circumstances governmentintervention is needed. Itis good to have only few players in one national contextbut not in another. Clarifying the range of intervention is perhaps most related to the tasks ofidentifying benefits and costs of access and how these are distributed.

One of the fastest growing technologies of our times is that of mobile phones. In Boretos's(2007) article, theassumption is that the diffusion of mobile technology, as measured by the number of active mobile accounts, followsthe well-known S-curve of natural growth in competition systems. The accuracy of the logistic fit is tested againstactual data for the whole world, Europe, China and the GSM system. Using the produced models predictionsconcerning the future of mobile business are deliberated.According to these models active mobile accounts around the globe are expected to grow from 1.7 billion in2004 to approximately 2 billion in 2008, reaching a peak penetration of $29.2 \%$. Growth barriers, apart from the ageof the potential user, are also low income and extreme poverty. Europe, early adopter of mobile technology andleader in active mobile accounts against all other 
regions in the world, has apparently reached a peak with almostevery European, apart from the very young or very old, using a mobile phone. The mobile market in China isanticipated to exceed 500 million active accounts and may increase even further depending on the economic andsocial reform that is currently under way in that part of the world. GSM will most likely remain the leading mobiletechnology in the future as it is today. The growth process for the world, Europe, and the GSM system is almost completed and during this stageinstabilities may occur before the potential emergence of a new wave of growth.

Mazzoni et al. (2007)'s paper investigates the characteristics of Italian cell phone users. A multidimensional segmentation approach wasadopted, using concurrently three sets of variables: consumer/user lifestyle, use motivations and product/service attributes. The study led to the identification of three user segments, each with a diverse combination of the segmentationvariables. Findings provide implications for the mobile telecommunication industry and could suggest strategic choices tomobile operators-especially cell phone producers - and constitute the basis for their strategic positioning.

Funk (2005)'s article utilizes the concepts of technological trajectories and lead users to forecastthe future of mobile phone Internet applications. These trajectories include the number ofpolyphonic tones, color display, camera resolution, Java program size, microprocessorspeeds, memory size, and network speeds. While some of these trajectories will diminish has user needs are met, it appears that increases in Java program size, microprocessorspeeds, memory size, and network speeds will have a strong effect on the expansion ofapplications for many years to come.These technologies are making the mobile phone a multi-media mail device, a portableentertainment player, a new marketing tool for retailers and manufacturers, a multichannelshopping device, a navigation tool, a substitute for tickets and money, and a newmobile intranet device.

\section{Data and Variables}

To conduct such a hedonic price analysis for mobile phones, data on 101 different handsets from 5 manufacturers has been collected. The data was assembled from the daily newspaper "Donyaye-eghtesad" in 9/15/2010. Apart from the prices that the handsets commanded in the Iran market for mobile telephones at the time of their market introduction, information on various characteristics such as the handset's weight, battery duration and additional features such as WAP, Radio and GPS has been collected.

Table 2 gives some descriptive statistics for variables used. Weight, call time, substitution time and CameraInPixel are ratio scale variables and others are ordinal scale variables. 
Table 2.Descriptive Statistics

\begin{tabular}{|l|l|l|l|l|}
\hline Variable & Mean & Std. dev & Min & Max \\
\hline PriceInTomans & 219783.78 & 134115.175 & 30000 & 693000 \\
\hline isNokia & 0.29 & 0.455 & 0 & 1 \\
\hline isSonyEricsson & 0.19 & 0.393 & 0 & 1 \\
\hline isHTC & 0.05 & 0.227 & 0 & 1 \\
\hline isLG & 0.14 & 0.343 & 0 & 1 \\
\hline isSumSung & 0.33 & 0.474 & 0 & 1 \\
\hline hasGuarrantee & 0.87 & 0.333 & 0 & 1 \\
\hline WeightInGram & 106.272 & 21.7335 & 66 & 181 \\
\hline isTouchScreen & 0.36 & 0.482 & 0 & 1 \\
\hline CameraInMegaPixel & 3.512 & 2.3933 & 0 & 12 \\
\hline CallTimeInHour & 7.001 & 2.5675 & 1.6 & 13 \\
\hline SubstitutionTimeInHour & 406.757 & 133.6339 & 5 & 800 \\
\hline hasRadio & 0.94 & 0.244 & 0 & 1 \\
\hline hasWireLess & 0.34 & 0.477 & 0 & 1 \\
\hline hasGPS & 0.35 & 0.48 & 0 & 1 \\
\hline
\end{tabular}

\section{Models Specifications and estimations}

\subsection{Hedonic Regression}

One of the important decisions in hedonic regression is selecting the form of the function in Eq. (2). Some often used functions are linear, quadratic, log-log, semi-log, exponential, Box-Cox. Till now, there has been no definite rule for choosing a function type in the hedonic price model. Researchers used several functional forms for the hedonic price function on the basis of goodness of fit. In some recent studies (Shimizu, Takatsuji, \& Ono, 2010), (Nerlove M. , 1995), (Chakravarty, Dogan, \& Tomlinson, 2006), (Lee, Park, \& Kim, 2003)see( (Kwak, Lee, \& Chun, 1996), (Goodman \& Kawai, 1982), (Mendelsohn, 1984)), nonlinear functions such as semi-log, log-log, and Box-Cox functions (Lee, Park, \& Kim, 2003)see (Box \& Cox, 1964) are used. In fact there is no specific function is required for the model because the chosen function is consistent with the economic theory (Lee, Park, \& Kim, 2003) see (Freeman, 1994).

In this study, we use linear function to present our model, because its adjusted $\mathrm{R}^{2}$ and $\mathrm{F}$-value is better than semi-log function. Model is presented in Tables 3 and 4.

We use SPSS 18 (PSAW Statistics 18) software Regression analysis.

\subsection{Artificial Neural Network}

In this study, we employ a feed forward network with one hidden layers. This layer has 30 processing elements (Neurons). The input variables are all variables in table 1 except PriceInTomans and the output variable is PriceInTomans. In the ANN model, we use Sigmoid 
as the transfer function. At the solution stage, we use MATLAB 7.8.0 (R2009 a) software.

\section{Results}

\section{1Hedonic Regression}

Table 3.Model Summary

\begin{tabular}{|l|l|l|l|l|l|}
\hline \multicolumn{2}{|l|}{} & Constant & isSonyEricsson & isHTC & isLG \\
\hline $\begin{array}{l}\text { Unstandardized } \\
\text { Coefficients }\end{array}$ & B & 48304.41 & -22290.28 & 129467.3 & -28542.42 \\
\cline { 2 - 6 } $\begin{array}{l}\text { Standardized } \\
\text { Coefficients }\end{array}$ & Beta & 22052.28 & 17530.41 & 26936.72 & 19609.79 \\
\hline t-value & & -0.0654 & 0.22 & -0.073 \\
\hline Sig. & 2.19 & -1.272 & 4.806 & -1.456 \\
\hline VIF & 0.031 & 0.206 & 0.000 & 0.149 \\
\hline Condition Index & & 1.43 & 1.125 & 1.363 \\
\hline
\end{tabular}

Table 4.Model Summary (cont.)

\begin{tabular}{|c|c|c|c|c|c|}
\hline & & isTouchScreen & CameraInPixel & CallTimeInHour & hasWireLess \\
\hline \multirow{2}{*}{$\begin{array}{l}\text { Unstandardized } \\
\text { Coefficients }\end{array}$} & B & 28582.31 & 27787.17 & 4125.44 & 104512.67 \\
\hline & $\begin{array}{l}\text { Std. } \\
\text { Error }\end{array}$ & 15361.16 & 3346.81 & 2735.32 & 17078.25 \\
\hline $\begin{array}{l}\text { Standardized } \\
\text { Coefficients }\end{array}$ & Beta & 0.1 & 0.5 & 0.08 & 0.37 \\
\hline \multicolumn{2}{|l|}{ t-value } & 81.861 & 8.303 & 1.508 & 6.12 \\
\hline \multicolumn{2}{|l|}{ Sig. } & 0.066 & 0.000 & 0.135 & 0.000 \\
\hline \multicolumn{2}{|l|}{ VIF } & 1.65 & 1.928 & 1.482 & 1.992 \\
\hline \multicolumn{2}{|l|}{ Condition Index } & 3.164 & 3.841 & 5.386 & 10.777 \\
\hline \multicolumn{4}{|c|}{ Adjusted $\mathbf{R}^{2}: 0.797$} & \multicolumn{2}{|l|}{ F-Value: 62.514} \\
\hline \multicolumn{4}{|c|}{ Dependent Variable:PriceInTomans } & & \\
\hline
\end{tabular}

Table 3 and table 4 present the results from the OLS regression analysis. The backward elimination procedure is used in choosing the variables. As a result, many variables in Table 2 are excluded in model (tables 3 and 4). The value of F statistics,62.514, which is statistically significant and confirms the statistical significance of this regression model. The value ofR ${ }^{2}$ is 0.797 , which means that the price change of mobile phone is explained by about $79.7 \%$ according to theindependent variables of our model.

We examined the variance inflation factor (VIF) and the condition index (CI) and we found that both theVIF and CI of our regression results are lower than 10 (only has Wireless variable's CI is above 10. That is not so important and doesn't create any effectiveness issues in our model.). In other words, the model is free from the multicollinearity problem (Lee, Park, \& Kim, 2003) see (Gnanadesikan, 1977), (Cook \& Weisberg, 1982). 
The estimated regression coefficients, for all variables(except isSonyEricsson and isLG) are positive as expected. It means that having more features results in high mobile phone price. The negative coefficient if for brand variables(dummy variables) and this will be discussed later.

The coefficient of isHTC variable is 129467. It means that mobile phone users pay 129467Tomans ${ }^{1}$ (\$129.5) more for this mobile phone brand relative to Nokia brand(because our base brand in this model is Nokia). Its main reason is that HTC mobile phones introduced some new features that mobile phone users that liked, accepted and used them. Unlike this, the coefficient of isSonyEricsson and is $L G$ is -22290 and -28542 respectively. It means that Nokia brand is popular than these two brands in the market. isTouchScreen variable's coefficient also shows that Iranian mobile phone users pay 28542 Tomans(\$28.5) more for Touch Screen mobile phones. Iranian users also pay 27787 Tomans(\$27.7) for every MegaPixel of Quality feature of mobile phone camera. It is reasonable to pay 4125 Tomans(\$4) for every hour of battery charge in Iran. In Iran, users are ready to pay as much as 10451 Tomans $(\$ 104.5)$ for Wireless network connectivity. One main reason is that nowadays wireless networks are widely used in Iran's Universities, Organizations, Institutions and some other public places.

\subsection{Artificial Neural Network}

After developing our ANN model, we gave our data set to both ANN model and Hedonic Regression model and examined the results of both models and the result is illustrated graphically in Figure 2. We calculated Mean Absolute Error(MAE), Sum of Squares Error(SSE) and Mean of Errors Rates(MER). In all of these indicators illustrate that ANN model is better than Hedonic Regression model(Figures 3, 4 and 5).

\section{Conclusions}

In this study, we examine the determinants of the mobile phone prices in the Iran market. We employ Hedonic Regression and Artificial Neural Network approaches in modeling. The results of hedonic model reveal that HTC brand, Touch Screen feature, Wireless Network connectivity, every Mega Pixel camera quality and Battery Life in calling positively affects the price of mobile phones. It's possible that hedonic function is nonlinear and because of that, we also employ Artificial Neural Network model as an alternative method for estimation. Comparing these two estimators demonstrates that ANN is a better alternative model for mobile phone price in the Iran market.

\footnotetext{
${ }^{1}$ One Toman is 10 Rials. Every USA dollar is about 10000 Rials.
} 


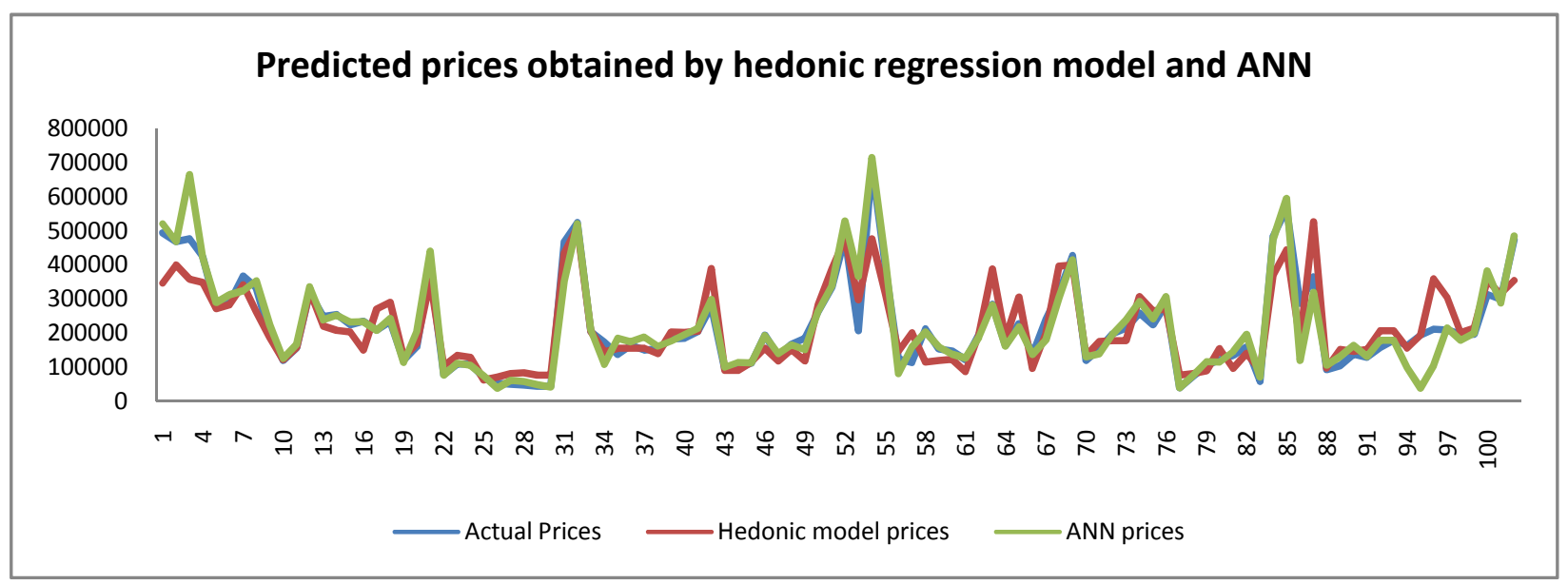

Figure 2. Predicted prices obtained by hedonic regression model and ANN

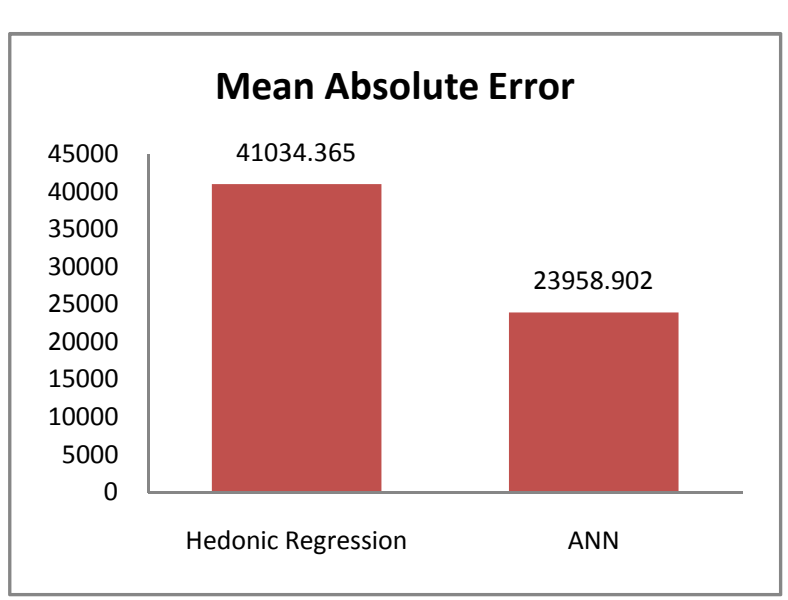

Figure 3. Mean Absolute Error

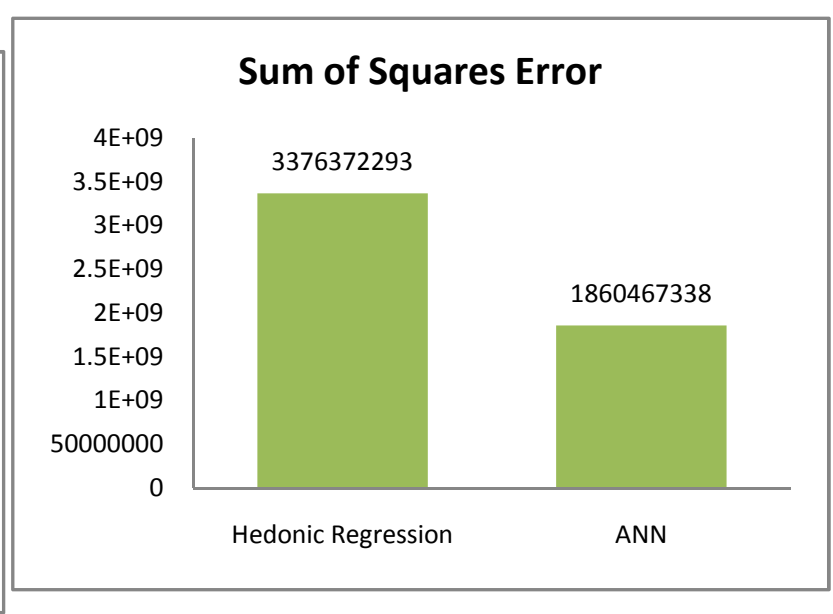

Figure 4. Sum of Squares Error

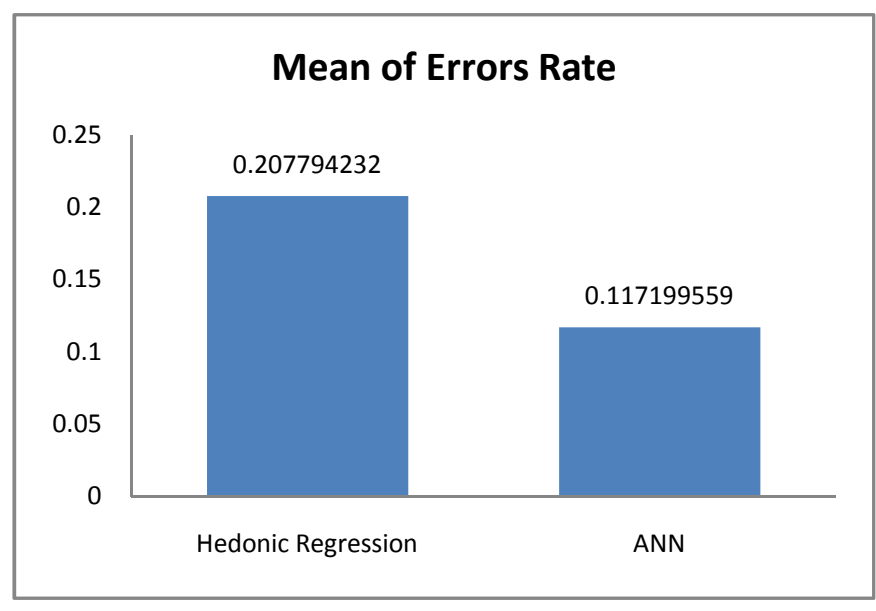

Figure 5.Mean of Errors Rate 


\section{References}

Asher, C. (1992). Hedonic Analysis of reliability and safety for new automobiles . Journal of Consumer Affairs 26, 377-396.http://dx.doi.org/10.1111/j.1745-6606.1992.tb00033.x

Berry, S., Levinsohn, J., \& Pakes, A. (2004). Differentiated products demand systems from a combination of micro and macro data: The new car market. Journal of Political Market,112, 68-105.http://dx.doi.org/10.1086/379939

Bonnetain, P. (2003). A hedonic price model for islands. Journal of Urban Economics, 54, 368-377.http://dx.doi.org/10.1016/S0094-1190(02)00506-5

Boretos, G. P. (2007). The future of the mobile phone business. Technological Forecasting \& Social Change 74, 331-340.http://dx.doi.org/10.1016/j.techfore.2005.11.005

Box, G., \& Cox, D. (1964). An analysis of transformations. J. Royal Statistics Soc. B26, 211-252.

Chakravarty, S., Dogan, K., \& Tomlinson, N. (2006). A hedonic study of network effects in the market for word processing software. Decision Support Systems 41, 747763.http://dx.doi.org/10.1016/j.dss.2004.10.010

Chwelos, P., Berndt, E. R., \& Cockburn, I. M. (2006). Faster, smaller, cheaper: An hedonic price analysis of PDAs. Applied Economics, , forthcoming.http://dx.doi.org/10.1080/00036840600993924

Cook, R., \& Weisberg, S. (1982). Residuals and Influence in Regression. Chapman and Hall.

Curry, B., Morgan, P., \& Silver, M. (2002). Neural networks and nonlinear statistical methods: An application to the modelling of pricequality relationships. Computers \& Operations Research, 29, 951-969.http://dx.doi.org/10.1016/S0305-0548(00)00096-4

Dewentet, R., Haucap, J., Luthar, R., \& Rotzel, P. (2007). Hedonic prices in the German market for mobile phone. Telecommunication Policy 31,4-13.http://dx.doi.org/10.1016/j.telpol.2006.11.002

Feenstra, R. (1995). Exact Hedonic Price Indexes. Review of Economics and Statistics 77, 634-54.http://dx.doi.org/10.2307/2109812

Freeman, A. (1994). The Measurement of Environmental and Resource Values: Theory and Methods. Resources for the Future, Washington, DC.

Funk, J. L. (2005). The future of the mobile phone Internet: an analysis of technological trajectories and lead users in the Japanese market. Technology in Society 27, 69-83.http://dx.doi.org/10.1016/j.techsoc.2004.10.001

Gnanadesikan, R. (1977). Methods for Statistical Data Analysis of Multivariate Observations. Wiley, 
Goodman, A., \& Kawai, M. (1982). Permanent income, hedonic prices and demand for housing. J. Urban Econ. 12, 214-237.http://dx.doi.org/10.1016/0094-1190(82)90016-X

Haeger, J., \& Storchmann, K. (2006). Prices of American Pinot Noir wines: Climate, craftsmanship, critics. Agricultural Economics, 67-78.http://dx.doi.org/10.1111/j.1574-0862.2006.00140.x

Hornik, K., Stinchcombe, M., \& White, H. (1989). Multi-layer feedforward networks are universal approximators. Neural Networks, 2(5), 359-366.http://dx.doi.org/10.1016/0893-6080(89)90020-8

Hung, S.-Y., Liang, T.-P., \& Liu, V. W.-C. (November 1996). Integrating arbitrage pricing theory and artificial neural networks to support portfolio management. Decision Support Systems, Volume 18, Issues 3-4, 301-316.http://dx.doi.org/10.1016/S0167-9236(96)80006-6

Hung, W.-T., Shang, J.-K., \& Wang, F.-C. (2009). Pricing determinants in the hotel industry: Quantile regression analysis. International Journal of Hospitality Management.http://dx.doi.org/10.1016/j.ijhm.2009.09.001

İşeri, A., \& Karlık, B. (March 2009). An artificial neural networks approach on automobile pricing. Expert Systems with Applications, Volume 36, Issue 2, Part 1, 2155-2160.http://dx.doi.org/10.1016/j.eswa.2007.12.059

Jandaghi, G., \& Hashemi, O. (2010). Modeling the selection of a product through its attributes by using probablistic neural networks and discriminant analysis. World Applied Science Journal 8 (8), 959-964.

Kwak, S., Lee, G., \& Chun, Y. (1996). Estimation of the benefit of air quality improvement: an application of hedonic price technique in Seoul. The Economics of Pollution Control, Edward Elgar, 171-182.

Lancaster, K. (1966). A New Approach to Consumer Theory. Journal of Political Economy, 132-57.http://dx.doi.org/10.1086/259131

Lancaster, K. (1971). Consumer demand. New York: Columbia University Press.

Lee, H. S., Park, K., \& Kim, S. Y. (2003). Estimation of information value on th Internet: application of hedonic price model. Electronic Commerce Research and Applications 2, 73-80.http://dx.doi.org/10.1016/S1567-4223(03)00002-4

Maurer, R., Pitzer, M., \& Sebastian, S. (2004). Hedonic prices indices for the Paris housing market. Allgemeines Statistisches Archiv, 88, 303-326.http://dx.doi.org/10.1007/s101820400173

Mazzoni, C., Castaldi, L., \& Addeo, F. (2007). Consumer behavior in the Italian mobile telecommunication market. Telecommunications Policy 632-647.http://dx.doi.org/10.1016/j.telpol.2007.07.009 
Mendelsohn, R. (1984). Estimating of structural equations of implicit markets and household production functions. Rev. Econ. Statistics 66 (4), 673-677.http://dx.doi.org/10.2307/1935993

Mobile phone prices page. (n.d.). Retrieved July 20, 2010, from Donyaye-eghtesad Daily news paper: http://www.donya-e-eqtesad.com

Nerlove, M. (1995). Hedonic price functions and the measurement of preferences: The case of Swedish wine consumers. European Economic Review 39, 1697-1716.http://dx.doi.org/10.1016/0014-2921(95)00013-5

Pakes, A. (2003). A reconsideration of hedonic price indexes with an application to PC's. American Economic Review, 93, 1578-1596.http://dx.doi.org/10.1257/000282803322655455

Pao, H.-T. (March 2007). Forecasting electricity market pricing using artificial neural networks. Energy Conversion and Management, Volume 48, Issue 3, 907-912.http://dx.doi.org/10.1016/j.enconman.2006.08.016

Rigall-I-Torrent, R., \& Fluvia, M. (2010). Managing tourism products and destinations embedding public good components: A hedonic approach. Tourism Management, 1-12.http://dx.doi.org/10.1016/j.tourman.2009.12.009

Rosen, S. (1974). Hedonic Prices and Implicit Market:Product Differentiation in Pure Competition. Journal of Political Economy 82, 34-55. http://dx.doi.org/10.1086\%2F260169" http://dx.doi.org/10.1086/260169

Selim, H. (2009). Determinants of house prices in Turkey: Hedonic regression versus artificial neural network. Expert Systems with Applications 36, 2843-2852.http://dx.doi.org/10.1016/j.eswa.2008.01.044

Shimizu, C., Takatsuji, H., \& Ono, H. (2010). Structural and temporal changes in the housing market and hedonic housing price indices. International Journal of Housing Markets and Analysis, Vol. 3 No. 4, 351-368.http://dx.doi.org/10.1108/17538271011080655

Sue, E. D., \& Wong, W.-K. (2010). The political economy of housing prices: Hedonic pricing with regression discontinuity. Journal of Housing Economics 19, 133-144.http://dx.doi.org/10.1016/j.jhe.2010.04.004

Thakur, D. (2011). Market competition and the distributional consequences of mobile phones in Canada. Technological Forecasting \& Social Change.http://dx.doi.org/10.1016/j.techfore.2011.04.013

Thrane, C. (February 2005). Hedonic Price Models and Sun-and-Beach Package Tours: The Norwegian Case. Journal of Travel Research, Vol. 43, 302-308.http://dx.doi.org/10.1177/0047287504272034 
Triplett, J. (1969). Automobiles abd Hedonic Quality Measurement. Journal of Political Economy, 85-103.

Ustaoglu, E. (2003). Hedonic price analysis of office rents: A case study of the office market in Ankara. Master of Science Thesis, Middle East Technical University, Turkey.

Waugh, F. V. (1928). Quality factors influencing vegetable prices. Journal of Farm Economics, 10, 185-196.http://dx.doi.org/10.2307/1230278 